Science, University of Arhus, Majvej 3, DK 8210 Arhus V, Denmark).

COMMENT. DAMP is a diagnostic term used predominantly in Scandinavia to describe the signs of minimal brain dysfunction that are frequently found in children with ADHD and that overlap with the developmental coordination disorder (DCD) listed in the US DSM-IV. This study demonstrates the importance of the neurologic examination in children with $\mathrm{ADHD}$, so that therapeutic intervention with occupational and physical therapy can be instituted at an early age. The "clumsy" child with ADHD has low self esteem, unless appropriate physical education activities and counseling are recommended early.

\title{
COMORBIDITY OF ADHD WITH BIPOLAR DISORDER
}

The age at onset of affective illness in 56 adults with a history of bipolar disorder was studied in relation to attention deficit hyperactivity disorder (ADHD) in childhood, at the Massachusetts General Hospital, Boston, MA. The age at onset of the first affective episode was lower in the 8 subjects with bipolar disorder and a history of childhood ADHD (mean 12.1 years) than for 8 subjects without a history of childhood ADHD (mean 20 years). (Sachs GS, Baldassano CF, Truman CJ, Guille C. Comorbidity of attention deficit hyperactivity disorder with early- and late-onset bipolar disease. Am I Psychiatry March 2000;157:466-468). (Reprints: Dr Sachs, Massachusetts General Hospital, WACC 812, 15 Parkman Street, Boston, MA 02114).

COMMENT. ADHD in children of adults with bipolar disorder might be a risk factor for the early development of bipolar disorder.

\section{PARENT/TEACHER CONCORDANCE FOR DIAGNOSIS OF ADHD}

The concordance between parent and teacher reports of DSM-IV attention deficit hyperactivity disorder (ADHD) and its symptoms was studied in 74 clinically referred children examined at Queens College, the City University of New York, and Mount Sinai School of Medicine, New York. Agreement between parents and teachers on structured diagnostic interview regarding diagnoses of $\mathrm{ADHD}$ is poor, and with no agreement for ADHD subtypes. Diagnosis based on either parent or teacher reports was positive for either inattentive or hyperactive-impulsive subtypes, but when both reports were used, most cases met only the criteria for ADHD combined type. Parent reports of behavior in school were more highly correlated with their child's behavior at home than with teacher reports of the child's behavior in school. (Mitsis EM, McKay KE, Schulz KP, Newcorn JH, Halperin JM. Parent-teacher concordance for DSM-IV attentiondeficit/hyperactivity disorder in a clinic-referred sample. I Am Acad Child Adolesc Psychiatry March 2000;39:308-313). (Dr Halperin, Department of Psychology, Queens College, 65-30 Kissena Blvd, Flushing, NY 11367).

COMMENT. Both teacher and parent questionnaires should be obtained for the diagnosis of ADHD subtypes, and one or other report alone is insufficiently reliable.

A family study perspective of DSM-IV ADHD subtypes showed that rates of ADHD among relatives of each subtype group were greater than rates among relatives of controls. Rates were not significantly higher among relatives of combined-typed probands compared to relatives of other probands. The subtype of the relative was not always the same as that of the proband, but hyperactiveimpulsive ADHD was found almost exclusively among relatives of hyperactiveimpulsive probands. The clinical differences among subtypes may be attributed to 
nonfamilial causes. (Faraone SV, Biederman J, Friedman D. LAm Acad Child Adolesc Psychiatry March 2000;39:300-307).

\section{MOVEMENT DISORDERS}

\section{TOURETTE SYNDROME, ADHD AND OTHER COMORBIDITY}

Tourette syndrome (TS) and its associated conditions are reviewed from University College and the National Hospital for Neurology and Neurosurgery, London, UK. Once considered rare, the prevalence estimate for Tourette syndrome is now given as 5 per 10,000 . For children in special education, the frequency of TS was $12 \%$ and tics occurred in $28 \%$. Comparing a group of 35 children in special education classes with 35 in regular classes, one study showed the incidence of tics was $26 \%$ and $6 \%$, respectively. The age of onset of TS ranges from 2 to 21 years, with a mean of 7 years. Motor tics usually precede phonic (or vocal) tics that have a later onset at 11 years. ADHD occurs in a large proportion of TS patients, ranging from 21 to $90 \%$ of clinic populations, and far exceeding the 2-19\% estimated in the general population. In recruits of the Israeli Army during 1 year, the rate of ADHD among those with TS was $8.3 \%$ compared with $3.9 \%$ in individuals without TS. Both ADHD and TS have a lower incidence with increasing age. Some forms of obsessive compulsive symptoms and behavior may be genetically related to TS. Self inflicting behavior is another comorbid disorder, related to TS and OCD. Other associated disorders include anxiety, depression, and personality disorders. Autosomal dominant inheritance or genetic heterogeneity are suggested but not proven. Environmental factors in etiology include pre- and perinatal insults, infections, and pediatric autoimmune neuropsychiatric disorder associated with group A b-hemolytic streptococcal infections (PANDAS). In addition to streptococcus, herpes simplex type 1 and Borrelia burgdorferi of Lyme disease have also been implicated, but not universally accepted in etiology. Tic symptoms are most severe at age 10 years and usually remit by late adolescence in 30-40\% of cases. Stress will exacerbate and prolong symptoms. Management includes supportive reassurance, relaxation training, and pharmacotherapy. A detailed review of medications and their side effects, with abundant references to studies are provided. (Robertson MM. Tourette syndrome, associated conditions and the compexities of treatment. Brain March 2000;123:425-462). (Respond: Professor Mary M Robertson, Department of Psychiatry and Behavioral Sciences, University College London, 2nd Floor, Wolfson Building, 48 Riding House Street, London W1N 8AA, UK).

COMMENT. The author is to be congratulated on a very complete review of the literature, supported by numerous references. In the author's clinic the most commonly prescribed medications in children with TS are clonidine in one-third, followed by sulpiride, haloperidol and fluoxetine. In the UK, most of the agents are neither recommended for children, nor licensed for use in TS. Many patients with milder symptoms require only reassurance and psycho-education.

Ziprasidone treatment of children and adolescents with Tourette's syndrome: a pilot study is reported from the Children's Hospital, Cincinnati. (Sallee FR, Kurlan R, Goetz CG et al. LAm Acad Child Adolesc Psychiatry March 2000;39:292-299). Ziprasidone was more effective than placebo in reducing global severity and total tic scores on the Yale Scale and video tic counts in 28 patients aged 7 to 17 years for a 56 day trial. An initial dose of $5 \mathrm{mg} /$ day was increased to a mean daily dose of $28 \mathrm{mg}$. Mild transient somnolence was the the most common adverse effect, and only 1 child developed akathisia. 